\title{
Mechanism of Roadway Floor Heave Controlled by Floor Corner Pile in Deep Roadway under High Horizontal Stress
}

\author{
Xinchao Kang $(\mathbb{D}$, Dongming Guo $\mathbb{D}$, and Zhiying Lu (iD) \\ School of Mechanics and Civil Engineering, China University of Mining and Technology (Beijing), Beijing 100083, China \\ Correspondence should be addressed to Zhiying Lu; lzy199@student.cumtb.edu.cn
}

Received 10 December 2020; Revised 12 January 2021; Accepted 27 January 2021; Published 11 February 2021

Academic Editor: Yi-Zhang Jiang

Copyright ( 2021 Xinchao Kang et al. This is an open access article distributed under the Creative Commons Attribution License, which permits unrestricted use, distribution, and reproduction in any medium, provided the original work is properly cited.

In order to overcome the support difficulty of serious floor heave caused by rock burst, with the floor heave of ventilation roadway in Hegang Xing An Coal Mine as the engineering background, the treatment scheme of the concrete-filled steel tube corner pile and floor grouting is put forward. Based on the solution of the slip line field under plane strain condition, the mechanical model of the slip-type floor heave is established, and the formula for calculating the critical failure depth of the roadway floor and the minimum support depth of the corner pile is derived. Through numerical analysis and similar model tests, the deformation and stress distribution of surrounding rock under the support of the corner piles are studied, and the force law of the pile under high horizontal stress is analyzed. The results show that, compared with the floor corner anchor, the floor corner pile + floor grouting support scheme can significantly improve the mechanical properties of the floor rock mass, and the plastic slip line of the floor plate part can be cut by corner piles, which effectively controls the deformation of the floor plate under high horizontal stress; the length and inclination angle of the corner pile have a great influence on the support effect. In the on-site treatment scheme, 1.1 times the calculated length of pile should be selected. The results of a similar model and field test show that the corner pile is effective in controlling the deformation of roadway floor and two sides.

\section{Introduction}

Among the problems in deep mining, the nonlinear mechanical phenomena caused by high ground stress have attracted the attention of many scholars at home and abroad [1]. Under the action of high horizontal stress, various obvious large deformation phenomena appear in surrounding rock of roadway. In the traditional support design, due to the consideration of economic factors, there is often little or no support stiffness distribution in the roadway floor. This causes serious floor heave in the roadway under the action of high horizontal stress, which affects the normal use of the roadway. When affected by other disturbance stresses, these phenomena can easily induce secondary engineering disasters such as roadway instability and floor water inrush, which seriously threaten the safe mining of coal resources.

At present, the existing research literature considers that the floor heave caused by high horizontal stress is mainly slippage type. According to the model test conducted by Yaodong et al. [2], the slippage type floor heave is caused by the flow deformation of fractured rock mass under high horizontal stress and the slip of surrounding rock under high stress parallel to bedding. At the same time, it is pointed out that the lithology of the floor, surrounding rock stress, support strength, and water conditioning are also the main factors causing floor heave. Through theoretical analysis, foreign scholars [3] believe that the essence of slippage type floor heave is the embodiment of unloading of deep rock mass and elastic energy release of rock mass during roadway excavation and put forward the failure criteria of floor rock mass through a large number of data statistics. In terms of calculation of slip dropsy, Kang [4] put forward the calculation formula of floor dropsy based on the flexion theory of plate, and $\mathrm{He}$ [5] introduced the calculation theory of large deformation into the calculation of floor heave.

On the basis of the research of sliding type dropsy mechanism, many scholars have put forward different 
control methods of dropsy in long-term practice. Gao et al. [6] proposed the concrete-filled steel tube (CFST) as the reverse arch support method, which achieved a good support effect on soft rock roadway. Kang et al. [7] proposed the combined support method of grouting at floor plate and placing anchor bolts at floor corner and solved relevant construction problems. Yang et al. [8] systematically studied the mechanical properties of different types of floor corner bolts under different stress states through laboratory tests. These techniques have achieved good support results under specific surrounding rock conditions. However, in certain high-level stress conditions, under the action of shear force, the anchor bolt is easy to bend and yield, which makes the supporting effect weaken obviously. Therefore, it is an urgent problem to find an economical and effective way of floor support.

This study is based on previous studies of sliding type floor heave under high stress, combined with the mechanical properties of CFST and the supporting method of CFST pile with floor corner plus grouting for floor plate is proposed. Based on the theory of slip field, the supporting mechanism of floor corner pile under typical stress field is analyzed, and its supporting effect is verified by the field test and a similar model test.

\section{Analysis of Mechanical Mechanism of Floor Corner Pile}

2.1. Establishment of Slip-Type Floor Heave Mechanical Model. In the process of roadway excavation, the unloading of roadway causes the stress state of surrounding rock to change from three to two directions. As the free face of roadway, the floor can only rely on its own strength to resist the horizontal stress under the condition of no support. In deep mining, because the higher horizontal stress exceeds the yield strength of the floor rock, the plastic zone of surrounding rock under the floor rock mass expands and connects to the floor, resulting in an overall plastic flow and symmetrical slip zone. As shown in Figure 1, when the base of roadway starts to enter the plastic zone state, the ABC region is in the state of uniform stress. When the stress on plane $\mathrm{AC}$ exceeds the yield strength of the $\mathrm{ABC}$ region, the rock mass in this region moves to the top of the floor together with the lower rock mass under the action of the lower rock mass, which causes floor heave in the roadway.

Different from shallow mining, pressure arch of a certain thickness is often formed in the position of roof surrounding rock after roadway excavation, and the stress of overlying surrounding rock is transferred to the floor through the arch foot. According to Platts' ground pressure theory $[9,10]$, when roof support resistance is not considered, the pressure arch thickness is $H$, as shown in the following equation:

$$
H=\frac{a \xi f+l \ln ((\gamma h+c \cot \varphi) / \xi c \cot \varphi)}{2 \xi f f^{\prime}},
$$

where $a$ is the width of roadway, $\xi$ is the triaxial stress coefficient in the laboratory, $f$ is the friction coefficient of the contact part between coal seam and roof, $l$ is the thickness of floor coal, and $C$ is the cohesion of the roof rock mass.

When the roadway floor is in the limit equilibrium state, the gravity of rock mass is ignored, and there is a uniform stress state in the triangle region $\mathrm{ABC}$. According to the More-Coulomb strength theory, the stress here is $\sigma_{\mathrm{ABC}}$, as shown in the following equation:

$$
\sigma_{\mathrm{ABC}}=\frac{c \cot \varphi}{1-\sin \varphi}
$$

where $c$ and $\varphi$ are the cohesion and internal friction angle of the soleplate region, respectively.

In the slip zone, the stress distribution is a degenerate Riemann problem, so it exists on the slip line, as shown in the following equation:

$$
\ln \sigma_{V}+2 \theta \tan \varphi=\ln \sigma_{\mathrm{ABC}}
$$

where $\theta$ is the angle between the glide line and the horizontal line. According to the hypothesis above, when the roadway floor is in the limit state, the rock mass in the slip zone is in the Rankine limit equilibrium state. Therefore, the value of $\theta$ is $\pi / 4-\varphi / 2$, which can be obtained by solving the differential equation:

$$
\sigma_{V}=c \cot \varphi\left(\frac{1+\sin \varphi}{1-\sin \varphi}\right)^{\pi \tan \varphi-1}
$$

where $\sigma_{V}$ is the ultimate strength of the $\mathrm{ABC}$ region. When the plastic zone of roadway floor is connected, the stress acting on the region is $\sigma_{C}$, as shown in the following equation:

$$
\sigma_{C}=\gamma\left(Z_{0}+H+H_{0}\right) K_{a}-2 c \sqrt{K_{a}} .
$$

Let $\sigma_{V}$ be equal to $\sigma_{C}$, which can derive the following equation:

$$
Z_{0}=\frac{1}{\gamma K_{a}}\left[c \cot \varphi\left(\frac{1+\sin \varphi}{1-\sin \varphi}\right)^{\pi \tan \varphi-1}+2 c \sqrt{K_{a}}\right]-H-H_{0},
$$

where $K_{a}=\tan ^{2}((\pi / 4)-(\phi / 2))$ and $H_{0}$ is the height of the roadway.

According to equation (6), the critical depth of roadway floor is closely related to the strength parameters of roadway floor and the self-weight stress of overburden rock mass. When the mass of floor rock mass is better, the critical depth is larger, and the rock mass in the floor area above $Z_{0}$ is in the state of elastic deformation, and there will be no slip-type floor heave. Pressure arch height and roadway height had the most obvious influence on critical depth, which also explained the cause of sliding floor heave in deep mining with high in situ stress.

2.2. Determination of the Slip Direction in the Slip Zone. As the assumption of continuous uniformity and isotropy is satisfied, the floor surrounding rocks naturally obey the associated flow rules [11]. According to the slip line velocity 


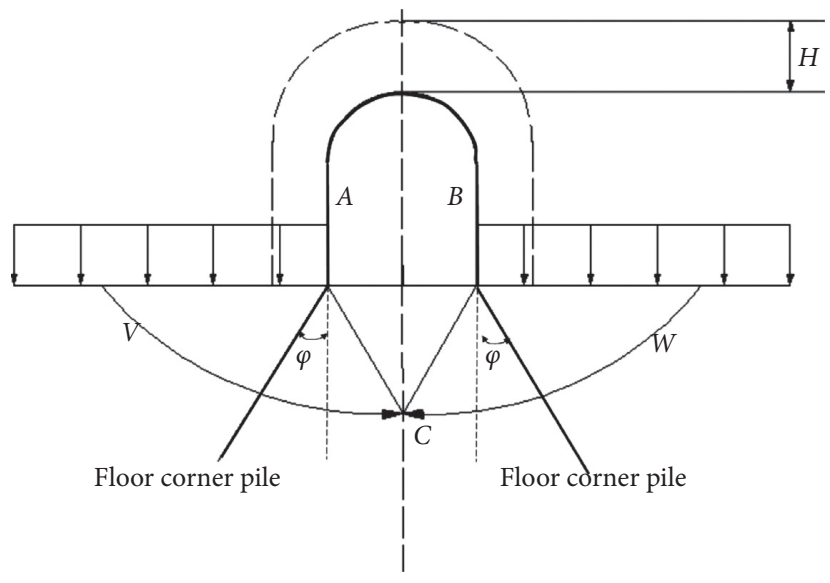

FIGURE 1: The mechanical model of roadway floor corner floor.

field theory, the velocity on the slip line $V$ and $W$ satisfies the following formulas:

$$
\begin{aligned}
& \mathrm{d} V_{v}+\left(V_{v} \tan \varphi+V_{w} \sec \varphi\right) \mathrm{d} \omega=0, \\
& \mathrm{~d} V_{w}+\left(V_{v} \sec \varphi-V_{w} \sec \varphi\right) \mathrm{d} \omega=0,
\end{aligned}
$$

where $V_{v}$ is the velocity of rock flow on slip line $V, V_{w}$ is the velocity of rock flow on slip line $W$, and omega is the angle of horizontal plane of slip line. Because the slip velocity of rock soil is small, only the slip angle of rock mass is considered in the design of floor corner pile. Therefore, the specific expressions of $V_{v}$ and $V_{w}$ are not considered in equations (7) and (8), but only the direction of velocity when stable slip is considered. So $\left(\mathrm{d} V_{v} / \mathrm{d} \omega\right)=0$, the slip zone enters into a stable slip state, and the solution is obtained:

$$
\omega=\frac{\pi}{4}-\frac{\varphi}{2}
$$

\subsection{Supporting Mechanism of Roadway Floor Pile and Con-} struction Plan. As can be seen above, after mining depth and roadway shape are determined, the strength parameters of roadway floor determine the critical failure depth and ultimate strength of roadway floor. Floor heave occurs when the stress exerted on floor rock mass by sliding area of roadway is greater than the ultimate strength of floor. The action mechanism of the traditional floor corner bolt is usually to cut off the slip line, but the stress barrier effect is always weak because of the material strength. As shown in Figure 2, pile at the floor corner of the roadway is driven at certain angles. The piles themselves are reserved with holes and the surrounding rocks are simultaneously grouting in the process of pile formation. In this way, on the one hand, the existence of piles cuts off the whole plastic flow of surrounding rocks and weakens the extrusion pressure acting on the floor; on the other hand, the ultimate strength of rock mass and floor compression area at the slip line is enhanced by grouting.

\section{Analysis of Mechanical Mechanism of Floor Corner Pile}

In order to verify the rationality of the theoretical analysis and analyze the influence of different design parameters on the support effect of floor corner pile, this study takes the geological conditions of the return air roadway of Hegang Xing An Coal Mine as an example and uses the finite-difference software FLAC3D to simulate the support effect of floor corner pile after roadway excavation.

3.1. Establishment of Numerical Model. The depth of transportation roadway in Hegang Coal Mine is about $450 \mathrm{~m}$, and the surrounding rock of the roadway floor is mainly mudstone. According to the theory of in situ stress in rock mechanics, the stress exerted on the model by overburden rock can be regarded as the self-weight stress of all overburden rock, so overburden stress $\sigma_{c}=\gamma Z=25 \times 0.45=11.25 \mathrm{MPa}$ and the lateral pressure coefficient is about 1.1. The section of the roadway is in the form of straight wall semicircle arch. Under the influence of high ground stress and rock mass properties, the floor heave is great. According to relevant examples, the influence range of roadway tunneling is $3 \sim 5$ times of roadway size $[12,13]$. As shown in Figure 3, the size of the model is determined as $60 \mathrm{~m} \times 120 \mathrm{~m} \times 20 \mathrm{~m}$. The displacement in the direction of $X Y Z$ is fixed at the floor of the model. Since the floor rock mass is assumed to be isotropic in theoretical analysis and the slip zone is considered to be in the Rankine state, the surrounding rock mass is taken from the Mohr-Coulomb model and simplified to three layers of rock mass. The rock mass of the roadway is sandy mudstone, the overlying strata of the roadway are sandstone, and the floor rock is sandy mudstone. The calculated parameters are shown in Table 1.

The floor corner pile is simulated by pile structure unit with the characteristics of open bolt due to its larger support stiffness and better flexural and shear performance. In this way, the support characteristics can be well realized in the calculation. The spatial arrangement of floor corner pile is shown in Figure 4. The constitutive model of pile element is 


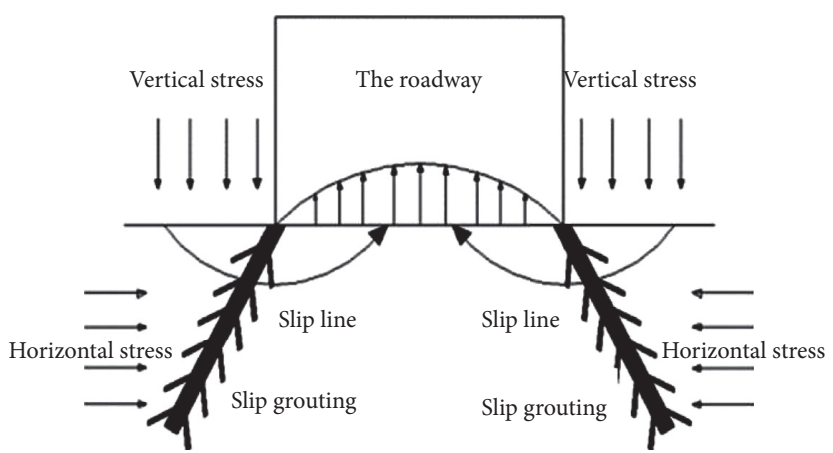

FIgURE 2: The support mechanism of floor corner pile.

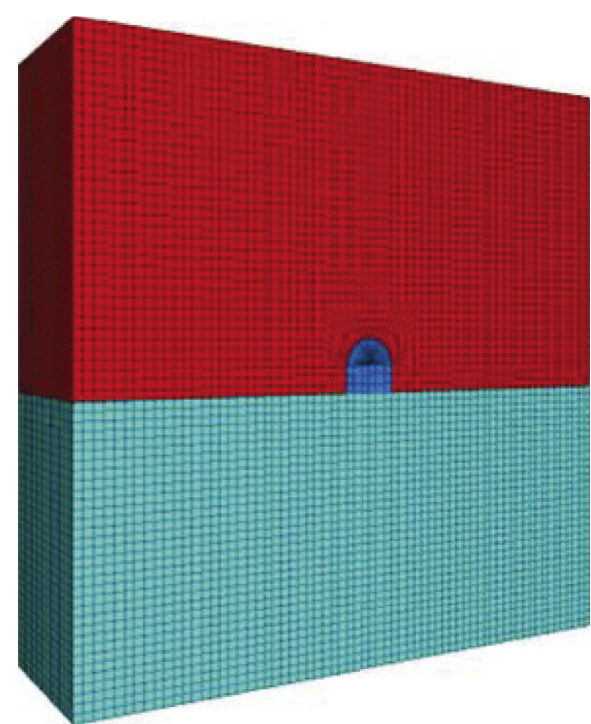

Figure 3: Numerical model.

TABLE 1: Mechanical parameters of the model.

\begin{tabular}{lccccc}
\hline Rock & Density $\rho\left(\mathrm{kg} / \mathrm{m}^{3}\right)$ & Bulk modulus $K(\mathrm{GPa})$ & Shear modulus $G(\mathrm{GPa})$ & Cohesion $c(\mathrm{MPa})$ & Internal friction angle $\varphi\left({ }^{\circ}\right)$ \\
\hline Mudstone & 2500 & 2.8 & 1.75 & 1.4 & 18 \\
Sandstone & 2480 & 3.6 & 2.25 & 2.58 & 34 \\
Sandy mudstone & 2510 & 4.2 & 2.7 & 1.8 & 31 \\
\hline
\end{tabular}

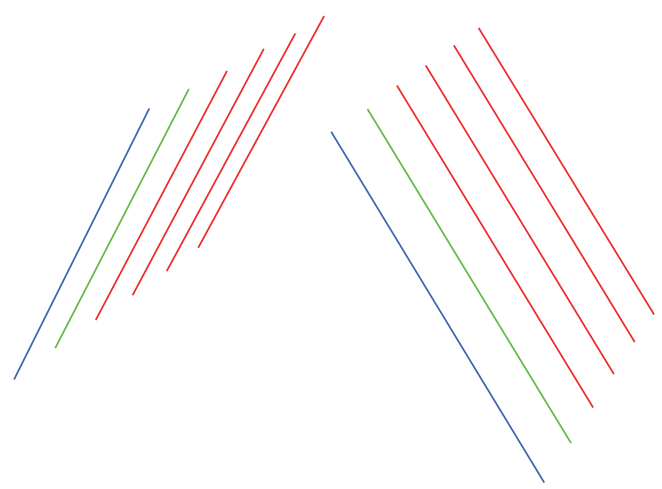

FIgURE 4: Space layout of the pile in the corner of roadway. 
the ideal linear elastic model, its elastic modulus is $108 \mathrm{GPa}$, and Poisson's ratio is zero 0.28 .

3.2. Setting of Simulated Working Conditions. The $Y$ direction of roadway is $20 \mathrm{~m}$. In the process of model tunneling, the length of each tunneling is $5 \mathrm{~m}$. In the process of excavation and support, a certain time step is set to simulate a certain time interval. In order to compare the supporting effects of floor corner anchor and floor corner pile, three working conditions are simulated, respectively, in the model: floor without support, floor corner anchor support, and floor corner pile support.

\subsection{Analysis of Calculation Results}

3.3.1. Plastic Zone Distribution of Floor under Different Support Conditions. The distribution of plastic zone of roadway can investigate the supporting effect of roadway surrounding rock under different supporting conditions. Figure 5 shows the plastic zone distribution of roadway under different support conditions. It can be seen from Figure 5(a) that, after roadway tunneling is completed, in the absence of floor support, except for a small part of the roof, the surrounding rocks all have a certain range of plastic areas, and the plastic area of the floor area is relatively significant. When the floor of the roadway is supported by the floor corner bolt, the plastic zone in the two sides and roof of the roadway mostly disappears. The shallow rock mass of the floor also presents elastic state, but the deep rock mass still yields a large area. This indicates that the floor corner pile can inhibit the expansion of plastic zone to a certain extent and strengthen the rock mass of both sides and roof while restraining the yield of floor rock mass. However, due to its weak resistance to bending shear, the resistance to flow in the plastic zone of floor is still relatively weak under high in stress. When the floor corner pile is driven into the floor corner, the bending shear yield strength of concrete filled in steel tubes is large, which can increase the support resistance. As can be seen from Figure 5(c), compared with the support effect of the floor corner bolt, the plastic zone of rock mass in the floor of the roadway moves downward significantly, and the elastic zone around the surrounding rock mass increases significantly.

\subsubsection{Support Effects under Different Design Parameters.} In order to analyze the influence of different pile lengths on the supporting effect of roadway floor, this study simulates the working conditions with floor corner pile lengths of $2.5 \mathrm{~m}, 3.0 \mathrm{~m}, 3.5 \mathrm{~m}$, and $4.0 \mathrm{~m}$, respectively. As shown in Figure 6, under different support conditions, the floor heave shape of the roadway was manifested as a small amount of floor heave at both floor corners and a large amount of floor heave at the middle, presenting a parabolic shape. When the length of the floor corner pile was $3.5 \mathrm{~m}$, which was close to the theoretical calculation value of $3.67 \mathrm{~m}$, compared with the unsupported state, the maximum floor heave in the roadway decreased by $800 \mathrm{~mm}$. With the increase of the pile length, the floor heave in the roadway decreased slightly, but the degree of decrease was not obvious. When the pile length was less than the theoretical calculation value, the roadway floor heave deformation was very sensitive to the change of pile length. When the pile length was $2.5 \mathrm{~m}$, the maximum floor heave of the roadway was $787 \mathrm{~mm}$, and when the pile length was $3.0 \mathrm{~m}$, the maximum floor heave of the roadway was $430 \mathrm{~mm}$, showing a great change. This is because when the pile length is small, the floor corner pile cannot completely cut off the floor corner slip line and can only block part of the slip body in the slip area, failing to achieve a good support effect.

The roadway floor heave at different support angles is shown in Figure 7. When the supporting angle of pile is $35^{\circ}$ with the vertical direction, the floor heave of roadway is the minimum, which is close to the theoretical value of $34^{\circ}$. When the angle between the pile support and the vertical direction is larger than the theoretical calculation value and is inclined to the horizontal direction, the floor heave of the roadway increases significantly. This is because when the pile at the floor corner is inclined to the horizontal direction, the slip line direction of the pile at the floor corner cannot provide enough support reaction force and thus cannot resist the plastic zone expansion better. When the supporting angle of floor corner pile is vertical compared with the theoretical value, the supporting resistance of pile is less weakened and the floor heave of roadway is not increased much. Therefore, when the site conditions cannot meet the design placement angle of the floor corner pile, it is advisable to drill the pile at the floor corner perpendicular to the floor plate.

3.3.3. Shear Stress on Floor Corner Pile. The internal force analysis of the floor corner can effectively optimize the design of the wall thickness of CFST pile and the ratio of core concrete. After the tunnel tunneling is completed, the shear condition of the pile body is shown in Figure 8, where the coordinate of the floor corner position is shown in the figure. When the length of pile is within $3 \mathrm{~m}$, the shear force of pile body increases gradually with the increase of depth and decreases slightly when the length of pile exceeds $3 \mathrm{~m}$. The reason is that, at the position of slip line, the tendency of rock mass sliding to the interior of the tunnel imposes a large shear force on the pile. The part of the floor corner pile embedded in the deep rock mass of the floor can be considered as a fixed constraint. The sliding rock mass of the floor rock exerts a horizontal shear force on the pile. According to the force behavior of the cantilever beam, the maximum shear force is borne by the part of the pile close to the constraint, so the shear force borne by the floor pile at the position of the slip plane reaches the peak value.

\section{Similarity Model Experimental Study}

Since the numerical analysis software FLAC3D takes the maximum unbalanced force as the convergence criterion in the numerical calculation, it is difficult to consider the variation of deformation with time after the roadway floor is used as the supporting structure. At the same time, it is 


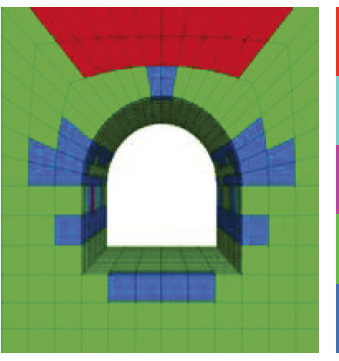

(a)

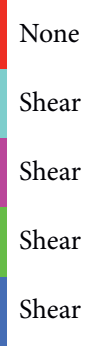

Shear

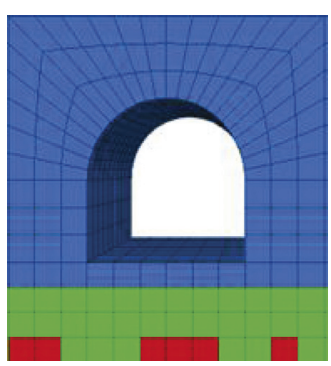

(b)

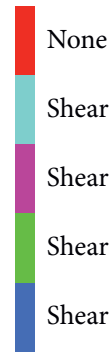

Shear

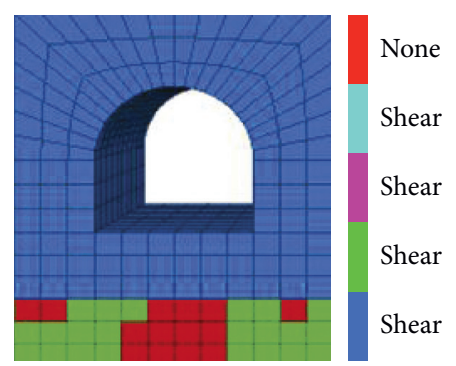

(c)

FIGURe 5: Plastic zone of roadway floor under different supporting conditions. (a) Plastic zone of roadway without support. (b) Plastic zone under floor corner pile. (c) Plastic zone under floor corner bolt.

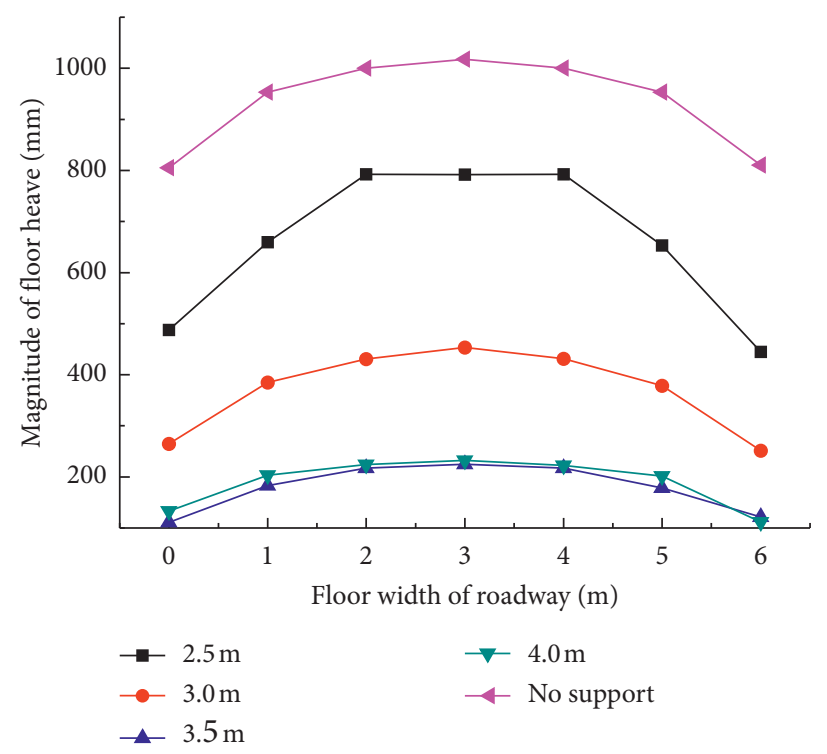

Figure 6: The magnitude of floor heave under different pile length.

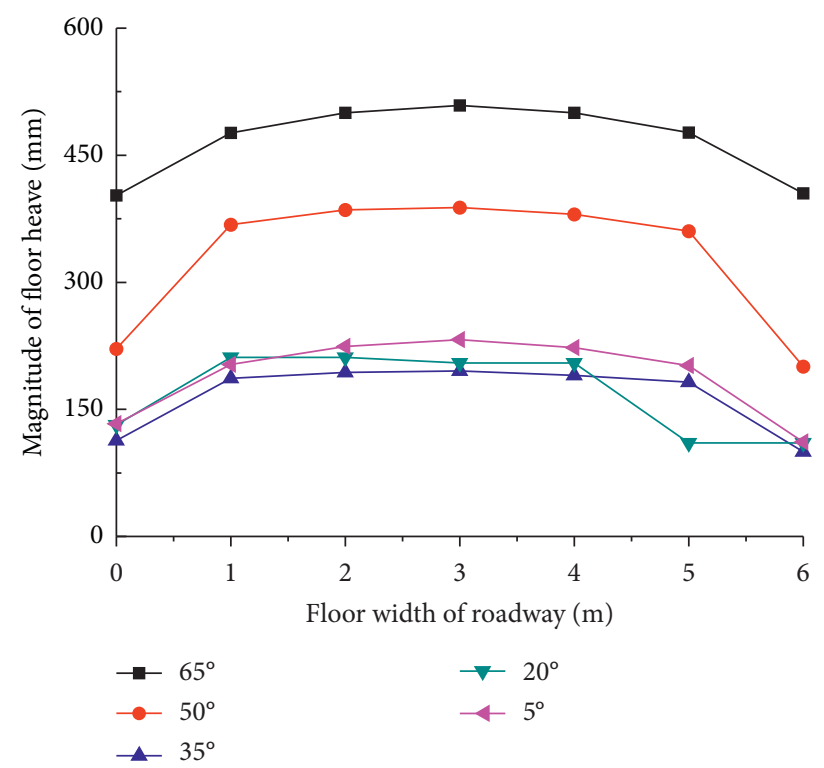

Figure 7: The magnitude of floor heave under different pile angle. 


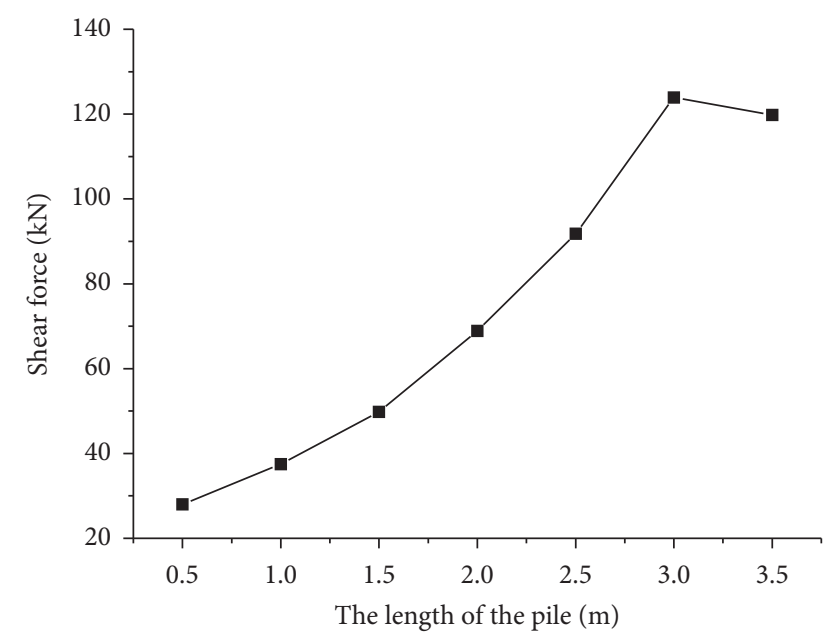

FIGURE 8: The shear value of pile in the corner of roadway.

difficult to analyze the floor grouting effect by numerical software. Therefore, in order to further study the supporting effect of floor corner pile, this study analyzes the convergence rate of roadway floor heave under the support of floor corner pile through a similar model test.

4.1. Establishment of Similar Model. The simulated working condition corresponds to the value analysis. In order to facilitate mold processing, the rectangular section is adopted for roadway section. High strength gypsum, fine sand, and water were used as the mixing materials in the tunnel model. In practical engineering, the coal mine roadway dimension is $5.5 \mathrm{~m} \times 4.5 \mathrm{~m}$, according to the laboratory test conditions and test equipment size, to determine the model test of similar ratio of 50, so the model of the size of the roadway to $11 \mathrm{~cm} \times 9 \mathrm{~cm}$. The model material density selected in this test is $1.5 \mathrm{~g} / \mathrm{cm}^{3}$, and the original rock density is $2.5 \mathrm{~g} / \mathrm{cm}^{3}$. According to the similarity criterion, the bulk density similarity ratio was determined to be 1.7 , and the similarity ratio of other parameters was determined by calculation. The mixing ratio of sand and gypsum was $1: 5$ and the model material of floor corner pile is cement mortar filled in aluminum tube.

The final model size was determined to be $6 \mathrm{~m} \times 5 \mathrm{~m}$, and the tunnel size was determined to be $11 \mathrm{~cm} \times 9 \mathrm{~cm}$. At the top of the model, a hydraulic press is used to realize the selfweight stress of surrounding rock, and stress brick is embedded in the middle of the model floor to monitor the deformation of roadway floor. Figure 9 shows the state of the model before and after excavation.

4.2. Analysis of Test Results. Through continuous observation of floor deformation, experimental values of similar models are recorded and converted into real values through the existing similarity ratio, as shown in Figure 10. When the roadway is not supported by floor corner pile, the change of floor heave with time can be roughly divided into three stages: the first stage starts from $1 \mathrm{~d}$ to $12 \mathrm{~d}$, and the change of floor heave with time is generally linear with a faster growth rate. The second stage began on the 13th day and ended on the 20th day. In this stage, the growth rate of floor heave gradually slowed down with time and gradually transitioned to the stationary stage. The third stage started from $21 \mathrm{~d}$, and the roadway floor heave began to converge and stabilized at about $1000 \mathrm{~mm}$. When the roadway was supported by floor corner pile, only $13 \mathrm{~d}$ was used to converge to the stable value, and the floor drum volume was stabilized to about $200 \mathrm{~mm}$, which was close to the numerical analysis results. By comparing the two working conditions with and without support, the floor corner pile accelerates the convergence of floor heave and reduces the initial growth rate of floor heave.

\section{Field Experimental Research}

The site test location was selected as the range from $23 \mathrm{~m}$ to $123 \mathrm{~m}$ south of the measuring point No. 5 of the first section of the return air roadway in the 4th horizontal 2-4 area of $\mathrm{He}$ Gang Xing An Coal Mine. Among them, the overall length of the test section is $23 \mathrm{~m} \sim 73 \mathrm{~m}$ for pile support and $73 \mathrm{~m} \sim 123 \mathrm{~m}$ for control section, as shown in Figure 11. The test section area is a weak bursting liability area.

According to the laboratory test results, geological conditions of Hegang Xing An Mine, and the above calculation formula, the overall construction technology of the floor treatment scheme is put forward as follows: floor corner drilling $\longrightarrow$ deep grouting of the floor$\longrightarrow$ construction of floor corner pile. The diameter of the floor hole is $200 \mathrm{~mm}$, the depth is $5.1 \mathrm{~m}$, the vertical pendulum is $35^{\circ}$, and the distance between the floor corner piles is $2.4 \mathrm{~m}$. In the process of drilling, if the hole collapses or is difficult to form a hole, the grouting pipe should be placed for pregrouting. After the surrounding rock of the roadway is stable, the construction shall be carried out until the hole is formed. After the completion of drilling, insert steel tubes with an outer diameter of $194 \mathrm{~mm}$ and a wall thickness of $12 \mathrm{~mm}$ into the holes, and the yield strength of the steel tubes shall not be less than $300 \mathrm{MPa}$. The floor plate grouting is completed by inserting the grouting pipe into the steel pipe. The grouting material is ultrafine cement grout, the watercement ratio is $2: 1$, and the grouting pressure is $2.5 \mathrm{MPa}$. When the grout is filled between the pipe wall and the borehole, the grouting shall stop. After grouting is completed, concrete is poured into the steel tube by a concrete pump. The concrete strength is $\mathrm{C} 40$, and the basic ratio is water : cement $:$ sand $:$ stone $=0.38: 1: 3: 6: 5.4$. The surface displacement of roadway was monitored on-site by the cross-point method. The location of the points was selected as the control section and the middle of the test section.

The displacement-time curves of the test section and the control section of the roadway are shown in Figure 12. Under the influence of mining stress in working face, horizontal stress of roadway increases sharply. From the time-displacement curve, the surrounding rock of the roadway deforms violently under the action of horizontal stress in the control section without pile support. Within $0-30 \mathrm{~d}$, the roadway floor and two sides deform rapidly. After entering a stable state, the floor heave of the roadway is close to $100 \mathrm{~cm}$, and the indentation of the two sides is as 


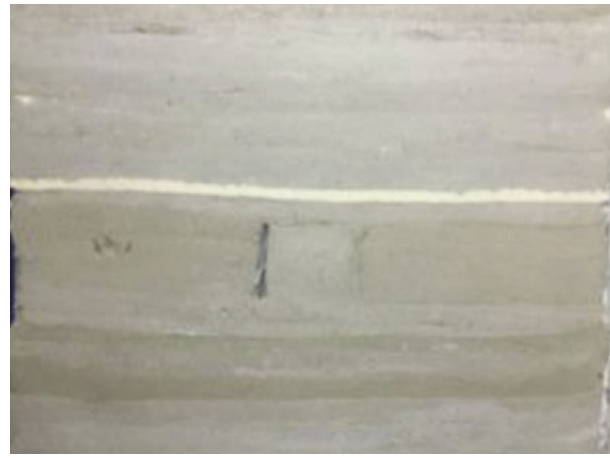

(a)

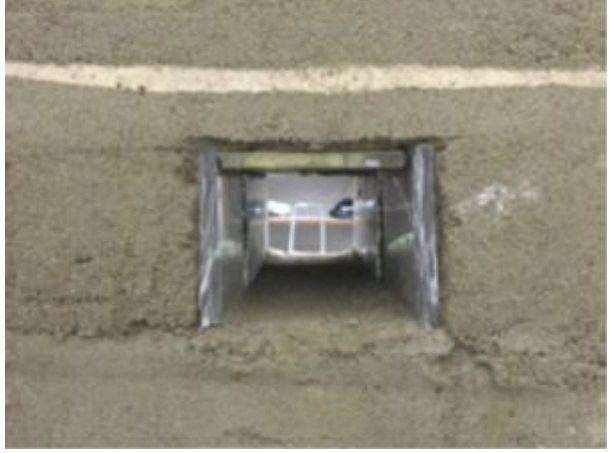

(b)

Figure 9: The state of roadway model. (a) Plastic zone under anchor bolt support. (b) The state of the model after excavation.

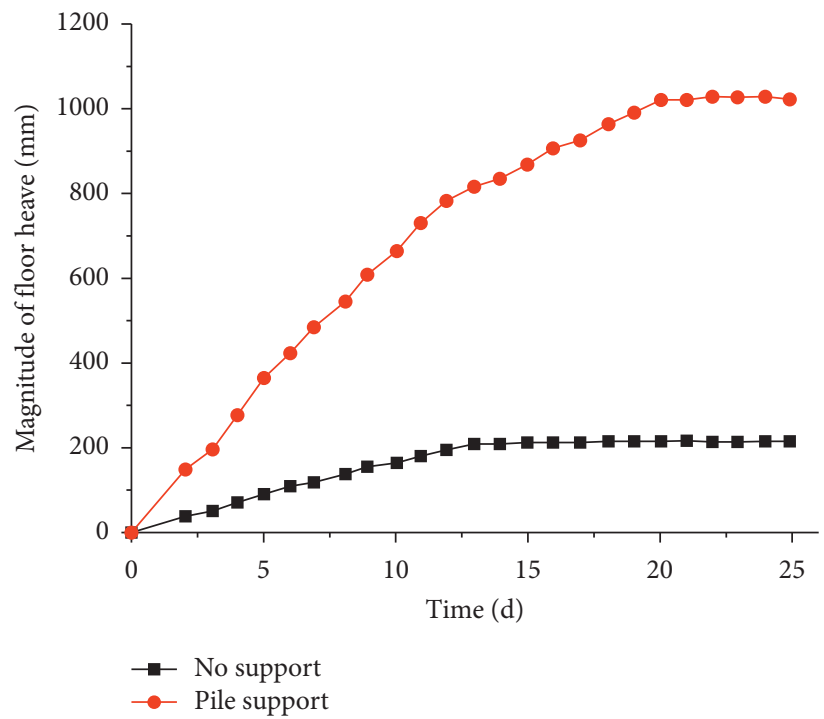

Figure 10: The law of floor heave changing with time.

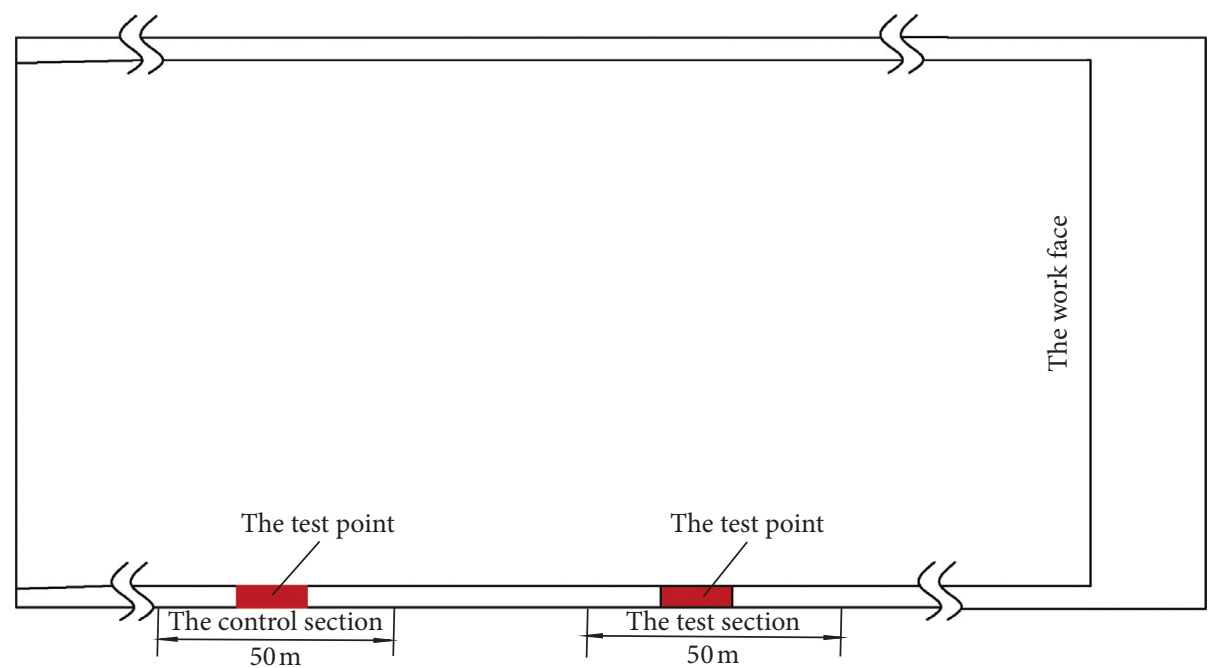

Figure 11: Layout of roadway test position and control section. 


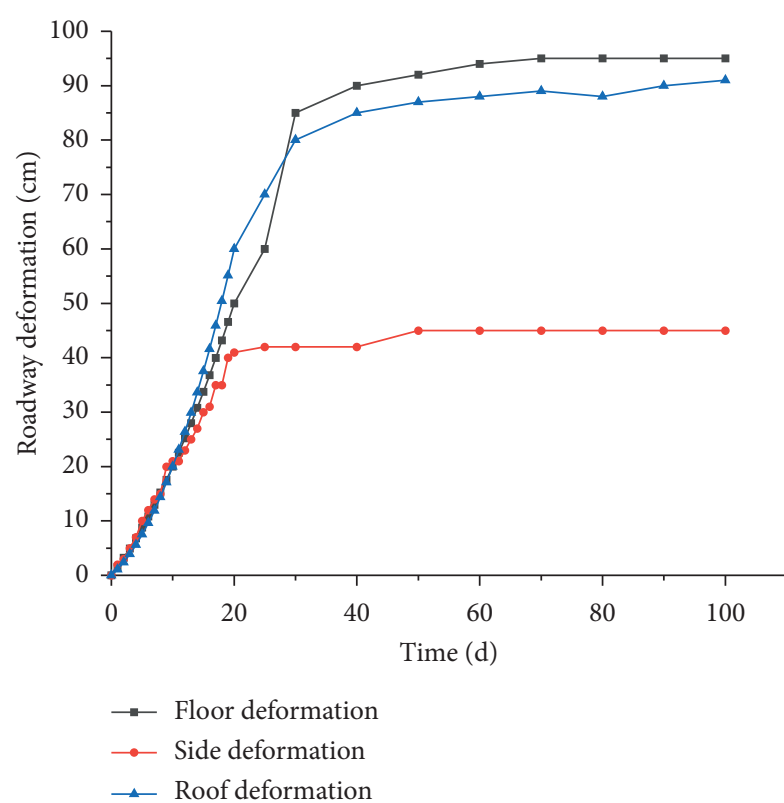

(a)

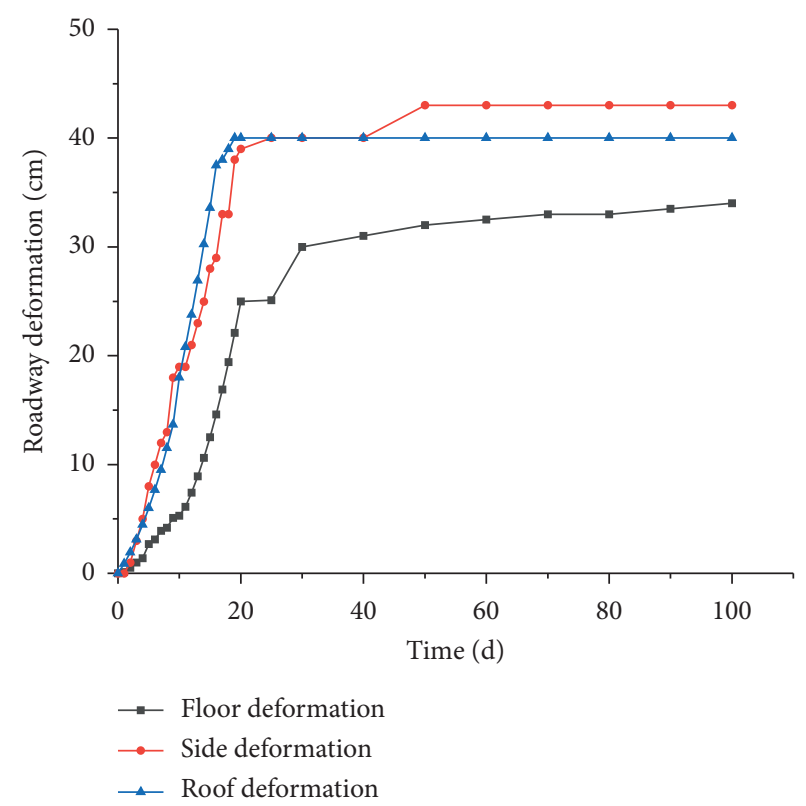

(b)

FIGURE 12: Displacement-time curves of roadway surrounding rock. (a) Deformation of the control section of the roadway. (b) Roadway deformation in the test section.

close as possible to $90 \mathrm{~cm}$. Only after capacity expansion can the roadway be normally used. Because the test section of the roadway was supported by the floor corner piles, the deformation of surrounding rock of the roadway quickly converged on the 20th day. Compared with the control section, the deformation of floor heave of roadway stability value dropped from $100 \mathrm{~cm}$ to $35 \mathrm{~cm}$, two stable indentations dropped to $40 \mathrm{~cm}$ by $90 \mathrm{~cm}$, and roof subsidence change is not big, which can satisfy the normal use of roadway.

\section{Conclusions}

Based on the sliding line field solution of plane strain and using Mohr-Coulomb strength theory, the critical failure depth of roadway floor under the action of horizontal stress and the formula for calculating the minimum length of floor corner pile are derived, which provides a theoretical basis for the design of floor corner pile.

Through numerical analysis software FLAC3D, the supporting effect of floor corner pile is simulated. The results show that pile length has a much greater impact on the supporting effect of floor corner pile than the inclination angle. In the roadway with complex surrounding rock strata, 1.1 times of the calculated length can be selected in the field treatment plan to be perpendicular to the rock strata layout.

Compared with the floor anchor rod, the floor corner pile of CFST can effectively cut off the sliding line of the floor due to its high bending shear capacity, and the grouting effect can significantly improve the mechanical properties of the floor rock mass, thus effectively controlling the floor heave.

The results of the similarity model experiment and field test show that when the roadway is in violent deformation under the action of high horizontal stress, the pile can accelerate the convergence of the deformation of the roadway and the two sides, control the deformation of the roadway and the two-side well, and improve the stability of the roadway significantly.

\section{Data Availability}

The data used to support the findings of this study are available from the corresponding author upon request.

\section{Conflicts of Interest}

The authors declare that they have no conflicts of interest.

\section{Acknowledgments}

This study was financially supported by the State Key Project of Research and Development Plan of China (2017YFC0804204) and the National Natural Science Foundation of China (51974315 and 51274204).

\section{References}

[1] Y. Jiang and Y. Zhao, "State of the art: investigation on mechanism, forecast and control of coal bumps in China," Chinese Journal of Rock Mechanics and Engineering, vol. 34, no. 11, pp. 2188-2204, 2015.

[2] J. Yaodong, A. Liqian, L. Yanhua, and C. Zhida, "Deformation analysis of laser spectra basdon S_R decomposition theorem," Applied Mathematics and Mechanics (English Edition), vol. 17, no. 11, pp. 1190-1199, 1999.

[3] C. Kang, "Key technologies for surrounding rock control in deep roadway," Journal of China University of Mining \& Technology, vol. 46, no. 5, pp. 1071-1081, 2017.

[4] H. Kang, "Sixty years development and prospects of rock bolting technology for underground coal mine roadways," 
Journal of China University of Mining \& Technology, vol. 45, no. 6, pp. 1071-1081, 2016.

[5] M. He, "Progress and challenges of soft rock engineering in depth," Journal of China Coal Society, vol. 39, no. 8, pp. 1409-1417, 2014.

[6] Y. Gao, B. Wang, J. Wang et al., "Test on structural property and application of concrete-filled steel tube support of deep mine and soft rock roadway," Journal of Rock Mechanics and Engineering, vol. 29, no. S1, pp. 1409-1417, 2010.

[7] H. Kang, J. Wang, and J. Lin, "Case study of rock bolting in coal mine roadways," Chinese Journal of Rock Mechanics and Engineering, vol. 29, no. 4, pp. 649-664, 2010.

[8] J. Yang, H. Shi, and Q. I. Gan, "Research on mechanism for floor heave control in the roadway by base-angel-bolt and its type selection test," Journal of Mining \& Safety Engneering, vol. 33, no. 4, pp. 643-648, 2016.

[9] L. Shao-wei, W.-G. Zhang, and Y. Feng, "Study on migration mechanism of slipping floor heave rock mass in deep roadway and its control countermeasure," Journal of Mining \& Safety Engneering, vol. 30, no. 5, pp. 706-711, 2013.

[10] G. Dongming, L. Kang, L. Lang et al., "Growth mechanism of original crack facing the blasting side of adjacent tunnel under the blasting load," Journal of Mining Science and Technology, vol. 2, no. 4, pp. 348-356, 2017.

[11] D. Guo, P. Yan, X. Lei et al., "The experimental research on the propagation laws of cracks in roadway surrounding rock subjected to static-dynamic load," Journal of Mining Science and Technology, vol. 1, no. 2, pp. 146-154, 2016.

[12] Y. Jiang, H. Song, Z. Ma et al., "Optimization research on the width of narrow coal pillar along goaf tunnel in tectonic stress zone," Journal of China Coal Society, vol. 43, no. 2, pp. 319326, 2018.

[13] K. Zhang, Y. Jiang, Z. Zhang et al., "Determining the reasonable width of narrow pillar of roadway in gob entry driving in the large pillar," Journal of Mining \& Safety Engineering, vol. 31, no. 2, pp. 255-262, 2014. 